\title{
The Social Impact of Ride-Hailing Technologies: The Experience of Passengers and Drivers in Jakarta
}

\author{
Godofredo Ramizo $\mathrm{Jr}^{1}$, Chotib $^{2}$ \\ \{godofredojr.ramizo@oii.ox.ac.uk ${ }^{1}$, chotib.m@ui.ac.id ${ }^{2}$ \} \\ ${ }^{1}$ Oxford Internet Institute, University of Oxford, United Kingdom, ${ }^{2}$ School of Strategic \\ and Global Studies, Universitas Indonesia, Indonesia
}

\begin{abstract}
Ride-hailing technologies such as Uber, Grab and GoJek have offered new solutions to commuters in Southeast Asia, including megacities such as Jakarta. Beyond the economic and commercial implications of these platform technologies, it is timely to empirically explore their social impacts as well. In this paper, we use triangulated qualitative methods such as interviews and direct participation to understand the impact of these technologies on the daily life of users such as drivers and passengers. We find that drivers and passengers enjoy many advantages ranging from superior functionality to improved socio-economic welfare. However, the drivers and users interact with the technology in ways that negatively affect the other. Both groups face challenges from technological issues, platform algorithms, and broader social realities. Aside from their empirical value, these findings can inform policies on how to socially integrate ride-hailing technologies in ways that best serve the social good.
\end{abstract}

Keywords: ride-hailing, Grab, GoJek, social impact, Jakarta

\section{Introduction}

Ride-hailing platform technology companies (RHPs) such as Uber, Grab and GoJek have offered new solutions to commuters in Jakarta. Most studies on ride-hailing apps look at North American and European cities, and there is comparatively less research on Southeast Asia. Existing studies on Southeast Asian contexts focus on the business, economic, and legal implications. There is a nascent but growing attention to the social effects of these ride-hailing platforms, specifically on the everyday experience of passenger and the drivers providing service. To contribute to the literature on the social impact of ride-hailing platforms in Southeast Asia, this paper inductively details the advantages and problems that are commonly faced by passengers and online drivers in Jakarta, capital of Indonesia and one of the few megacities in Southeast Asia. To deeply understand the situation of passengers and drivers, we gathered qualitative data through semi-structured, in-depth interviews with users and drivers. Through ethnography, we also directly and extensively used ride-hailing platforms and Jakarta's public transport to better understand the conditions on the ground. Due to the exploratory nature of our aims, and the novelty of ride-hailing platforms in Southeast Asian megacities as a research area, we did not limit our investigation to deductive constructs prescribed by pre-existing frameworks developed in other fields. Instead, this paper inductively looks at the experiences of passengers and driver with the technology itself, as well as the full experience interacting with the services 
on the platform. The aim is to explore the widespread impact of ride-hailing platforms on passengers and drivers, and gather empirical findings with practical and policy implications.

The subsequent section discusses the relevant literature, while section III outlines the objectives and research questions. Section IV elaborates on the methods used. Section V presents the research findings, which show the positive and negative effects of ride-hailing technologies on passengers and drivers. This paper ends by outlining some policy implications.

\section{Literature Review and Research Questions}

Some studies have described the adoption of ride-hailing platforms into the daily life of users in Jakarta. Perceived usefulness is often found to influence intent or actual uptake of ridehailing platforms in cities such as Jakarta [1]. There is also some effort to compare amongst individual RHP companies. Using a survey with 63 respondents undertaken in Jakarta through accidental sampling, a study suggests GoJek is superior to Grab in terms of user experience [2]. Sentiment analysis of 61,721 tweets on GoJek and Grab in Indonesia finds that relative to the total number of tweets about each app, GoJek receives 10\% more positive tweets than Grab. The authors then take this to mean that GoJek has better service quality than Grab in Indonesia [3]. In stark contrast, another study which calculates net sentiment scores from 126,405 tweets in Indonesia argues that customer satisfaction is higher for Grab compared to GoJek [4]. Very similar methods used on the same empirical domain may have resulted in inconsistent findings because society's experience with ride-hailing platforms has changed through the different time periods considered by these studies.

There are also studies that look at the social and economic impact of online transport from a variety of disciplines and lines of inquiry. A study from Universitas Indonesia estimates that the platform economy, including online transport companies Grab and GoJek contributed US\$ 3.3 billion to Indonesia's economy in 2018 alone [5]. Another study used convenience sampling to survey commuters and drivers of transport vehicles in Jakarta's central district [6]. Surveyors hired by the researchers approached commuters taking public transport vehicles and online transport vehicles, as well as the drivers of said vehicle. The 171 passenger respondents gave higher safety and satisfaction ratings to online transport services such as GoJek compared to conventional modes of transport. The usage patterns gathered from the survey present some evidence that ride-hailing platforms both replace, compete with, and complement traditional mass transport systems, disproving the notion that ride-hailing platforms only play a complementary role. Gunarwati and Kurnia aimed to understand in a somewhat open-ended way the consequences of Uber's entry into Jakarta's transport sector [7]. They employed a triangulated ethnographic approach - which involves the authors taking some trips using Uber, in addition to literature reviews and in-depth interviews with the drivers and users of Uber. One of the study's main findings contend that Uber is "mostly used by the middle-class community to feel the experience previously reserved for the "upper-class community"'[7]. Uber offers the sensation and feeling of having a personal driver without necessarily having one. Furthermore, Uber provides a more competitive price compared to taxis. The study's general argument is that since Uber is an information capitalist and Jakarta has transformed into an informational society where information capitalism is especially powerful, then Uber has enhanced capability to entice users while remaking labor relations and resisting the state. 
There have also been studies that look at the problems faced by Indonesian passengers. A sentiment analysis of tweets related to Grab and GoJek in Indonesia finds that common complaints on Grab pertain to unusable promotions, lack of response from customer support, and errors when claiming fare bonuses through the app. Whereas for GoJek, the main complaints include application problems, inability to get a ride, and difficulties logging in.[3] Increased incidence of application errors during rush hours further reduces the usefulness of these apps to commuters.[2] These efforts to tease out areas of dysfunctions are important because highlighting the problems paves the way for solutions.

However, some research areas need more attention. First, there seems to be less attention to the issues encountered by drivers. Second, many studies are restricted to one ride-hailing platform. Third, we focus on understanding deeply and inductively the various problems faced by users and drivers, soliciting from them the issues experienced in their daily life, rather than framing their experiences from a narrower set of deductive hypotheses imposed by applying pre-existing frameworks. Fourth, many of the studies cited above are conducted from previous years. In a fast-moving industry such as online transport, more recent research are likely to capture timely issues and concerns that are not yet discernible in the early years of online transport. Hence, this paper asks:

What are the positive and negative impacts of ride-hailing platforms on passengers and drivers?

\section{Methodology}

\subsection{In-depth Interview}

Strictly relying on frameworks such as the Technology Acceptance Framework or frameworks from other fields imposes a limited number of variables through which the phenomenon is studied. This hinders us from capturing the full breadth of people's experiences and useful insights on a phenomenon that is not yet well understood. Hence, this paper uses inductive methods such as in-depth, semi-structured interviews to explore the phenomenon and pursue leads coming from users that would have otherwise been missed by deductive applying pre-existing frameworks. Hence, this study conducted in-depth semi-structured interviews. In a semi-structured interview, the researcher loosely follows a questionnaire but also encourages participants to introduce topics they deem necessary. This allows the researcher to gather information on matters considered important before the interview, as well as capture new insights that are of empirical and theoretical interest [8].

Six (6) ride-hailing app users from Jakarta were initially gathered through snowball sampling. This pilot study helped determine the kinds of variation that must be included during face-to-face data gathering. Students and workers were identified as the main categories that were considered in the sample because these groups constitute the majority of commuters. The pilot study also indicated the value of considering variations in work schedule (day shift and night shift), and fixity of workplace, which refers to whether a worker has a single workplace or travels through different workplaces in a workday. Another desirable characteristic in the ideal sample is high variability in terms of home location, places of work or study, income level, and frequency of use, among others. Maximum variability is necessary because we learn little about the range of experiences involved if all interviewees have very similar profiles. For 
example, if all interviewees are all high income, young, male workers living in Pancoran and working in Sudirman, then we miss the opportunity to capture the experiences of women, older users, middle-income users, and workers with different travel patterns.

In quantitative research, researchers often obtain a random sample through probabilistic sampling, with the aim of generating inferential statistics and achieving generalisable figures. However, the goal of this study is not to produce generalisable statistics about ride app user adoption and the like. Instead, this study aims to capture how ride apps are impacting users using detailed explanations from interviewees, rather than numbers. Moreover, getting hold of a random sample is extremely problematic. The impossibility of obtaining a registry of ride app users (ride app companies will never divulge this confidential information), as well as the huge cost of interviewing a big enough sample are serious constraints.

Hence, we used sampling strategies that appropriate to qualitative studies. In particular, the participants were gathered through purposive sampling, a method of selection whereby diverse groups relevant to the research questions are purposefully selected from a pool of participants [8]. Under this method, we gathered prospective participants and interviewed carefully selected workers and students in Jakarta who use ride-hailing apps, and at the same time, exhibit variability in terms of the characteristics determined during the pilot study as important - such as age, income, travel patterns (mainly residence to place of work), gender, time of travel, and frequency of use. Some strategic choices were made to gather respondents who are likely to exhibit high variability. To include students in the study, participants were recruited from the University of Indonesia, in both Salemba and Depok Campuses through students chat groups within the university's departments. Being the premier public university of the country, the University of Indonesia attracts students from all income groups and even from far-flung districts around Jakarta, thereby providing variability to the sample in terms of income level and home location, among others. Moreover, since the Salemba campus is at the centre of Jakarta, people from nearby areas agreed to be interviewed at the Salemba campus. In addition, invitations to the general public to join the research were sent out through various social media channels.

A total of 125 user-passengers in Jakarta expressed interest in participating. Keeping in mind the desired variability in terms of characteristics mentioned above, we conducted 28 users from this pool of participants. The six (6) interviewees from the pilot study, and these 28 users selected through purposive sampling constitute the 34 user interviews used in this study. The interviews lasted 1 to 1.5 hours. We completed 34 user interviews, at which point we reached saturation - a concept in qualitative research which refers to that point where interviewing more respondents further corroborates existing data but no longer adds something new [8]. In other words, user interviews confirm each other to a very high degree, and therefore the data have high empirical reliability and reflect the experiences of people who share the same characteristics of the research participants. We also interviewed seven (7) online drivers who were recruited through snowball sampling via our contacts.

The sample for passengers achieved good variability on all important variables. Ten males and 24 females participated. There were eight (8) students, some of whom work, and the remaining 26 are either employees, entrepreneurs, retirees, or unemployed. The age ranges from 19 to mid 50's, with an average of 27. They either live or work in all five districts of Jakarta: South, West, East, North and Central Jakarta. Hence, the participants in the sample have deep experience with a large number of major and minor routes weaving across Jakarta. Some come from or work in the areas around Jakarta proper, such as Depok and Tangerang. The participants also come from varied backgrounds in terms of income level, educational background, and occupations. Respondents hail from a wide variety of backgrounds and bring rich personal 
stories: civil servants, itinerant consultants, gig workers, working mothers, retired pensioners, struggling rank and file employees, and entrepreneurs, among others. Such a diverse sample has allowed the study to gain a comprehensive understanding of the ride-hailing and highlight the credible, well-corroborated patterns that exist in the heterogeneous sample.

\subsection{Direct Observation and Fieldwork}

To triangulate the data gathered through interviews, the principal researcher conducted direct observation in Jakarta for four months and two weeks. He immersed himself in the life of a commuter, extensively using rival ride-hailing platforms such as Uber and Grab, as well as conventional modes of transport along major and minor routes. He took 185 ride-hailing trips, travelling for at least $1400 \mathrm{~km}$. He used ride-hailing apps according to the needs of the moment; but to better understand the complexity involved, he also took ride-hailing apps under several pre-selected conditions and those that appeared relevant during data-gathering. Consequently, he has tried RHPs during the morning, and evening rush hour, very late at night, during the wee hours of the morning, amid inclement weather, floods, through extreme traffic, while carrying heavy items, during weekdays, weekends, holidays, and emergencies, among others. He purposefully took rides during these various conditions to have a robust understanding of ridehailing. He also experienced spontaneous interactions with drivers, passengers, security guards, traffic enforcers, street vendors in a way that is within the range of normal daily behaviour, but still yielded telling details about the complex workings of conventional transport and ridehailing platforms.

\section{Results}

\subsection{Advantages Experienced by Passengers}

Time Savings. All interviewees share that online transport has generated time savings for them. They can find rides faster through the app's matching system. In contrast, they have to wait for TransJakarta and Commuter Line trains to arrive at designated stops, or for taxis and angkots to pass by. The trips in online transport vehicles are also faster not only due to the ability of two-wheeled vehicles to maneuver around traffic, but also because of allied navigation technology such as Google Maps and Waze, which show the driver shortcuts that avoid traffic congestion. Consequently, users have more free time or get to spend more time at home with their families.

Convenience and Comfort. All interviewees confirm that online transport offers superior convenience over most other conventional modes of transport. Convenience is often understood and described by interviewees as being able to quickly get a ride that directly transports them to their end destination. Online transportation allows them to avoid multi-modality, or having to use multiple modes of transportation such as angkot, TransJakarta, and Commuter Line just to get to one destination. Direct origin to destination conveyance also allows users to avoid other unpleasant steps in multi-modal transport such as having to walk between different stops, being exposed to heat, pollution, and inclement weather. Consequently, online transport helps office workers and front-facing employees to maintain a presentable appearance to their clients. 
For the many residents of Jakarta who come from other provinces, the apps allow them to reach their destination even if they know little about Jakarta's routes and transport system. For example, they do not need to know which modes to take, which bus number to ride, and at which stop to alight. Neither do they need to ask strangers for directions - a social interaction which some interviewees see as unpleasant and something to be avoided if possible. Another unpleasant social interaction that users avoid through the help of transport apps is haggling and bargaining with conventional ojek and bajaj for the fare as the app's algorithm handles the computations automatically. Moreover, the availability of online transport gives users an alternative option, which allows them to walk away from conventional ojek and bajaj drivers who charge too much. After all, they can book online transport instead. Conversations with online drivers can also be fun, adding to users' positive perception of online transport.

Pursuing New Activities and New Possibilities. Many users disclose that the availability of online transport has allowed them to engage in new activities, or perform certain roles better. For example, some users are better able to frequently visit their friends, family, and old parents, thereby improving their personal relationships. Likewise, the time saved through online transport has helped parents to allocate more time for child-rearing or running the household. The increased ability to go to church or other religious activities due to the ease offered by online transport has also been cited. Some users are also better able to pursue income opportunities such as taking in more clients, or providing services in faraway places or do so more frequently due to the speed and flexibility of online transport. Those aspiring to take further studies while working find that online transport helps them juggle their various responsibilities. Lastly, interviewees consistently corroborate that the availability of online transport has encouraged them to visit new places, malls, restaurants and, leisure establishments more often.

Safety. Better safety has been mentioned during the interviews as an advantage of online transport, but only by a few users interviewees. Most interviewees book two-wheeled motorbikes rather than sedan cars. As mentioned above, the risks associated with two-wheeled vehicles also apply in online two-wheeled taxis, such as over-speeding, possibility of injury, and reckless driving, among others. Moreover, major taxi companies such as Bluebird enjoy a good reputation among interviewees. Therefore, the difference in terms of safety between online transport and taxis may not be very noticeable to users.

\subsection{Issues and Problems Encountered by Passengers}

This section discusses the findings in terms of the difficulties and problems users face in online transport. These issues are categorized according to the following: driver behaviour, technological imperfections, platform behaviour, externalities, and the problems coming from the passengers' own perceptions and characteristics.

Issues with Driver Behaviour. Some drivers do not adhere to known platform rules and acceptable social norms. Interviewed users report that they experience booking cancellations by drivers. The ride-hailing system motivates drivers to have the trip canceled by making the user do it - through polite requests, coercion, and even deception. In the earlier days of ride-hailing in Jakarta, some drivers would deliberately delay clicking the "End Trip" button even after the passenger had alighted to increase the credit card charge further. However, ride-hailing companies have remedied this by introducing fixed fares. Users complain of occasional drivers 
who exhibit rough language and rude behaviour. There are complaints from female users that male drivers make inappropriate remarks. Interviewees also corroborate the suspected existence of a "ghost app" - a supposed hack into the platform's algorithm by sophisticated coders in connivance with a particular group of drivers. The ghost app is believed to assign bookings to conspiring drivers even if they are far from the passenger's pick-up point.

Some driver behaviours undermine the safety and convenience of commuters. Drivers, especially of two-wheeled transport, are repeatedly described as driving recklessly and squeezing between vehicles. Although rare, a few users have seen drivers who were nearly asleep due to exhaustion after trying to reach the number of trips required to gain incentives. The vehicle registered in the app is sometimes not the same as the vehicle brought by the driver. Likewise, the driver in the apps does not match the person driving the car. Some drivers who pick up or drop-off passengers in unsafe areas. Some drivers stubbornly refuse to use navigation apps and rely instead on their personal knowledge of the city, often causing delays to the passenger. In other cases, drivers do not know how to use navigation apps. Some drivers also do not keep their equipment in a good and hygienic condition. Helmets can sometimes be unhygienic, or the helmet buckles broken and impossible to adjust, which poses safety risks for riders.

Technological Issues. The Global Positioning System (GPS) technology used in locating the user and the driver's location, and marking pick-up and drop-off points sometimes return false coordinates on either the passenger or driver's smartphone. Hence, users experience difficulties in tracking the driver as it heads to the pick-up point, or finding the driver once it arrives. Sometimes, the pick-up point suggested by the GPS-driven functionality in the app is not the one closest to the passenger. Moreover, the apps freeze, or the log-in process fails. These app errors are presumably due to bugs in the software, hardware issues on the part of the user's smartphone, or the failure to download the latest update from platform companies. Another problem is that not all users have smartphones that are advanced enough to handle succeeding updates and app improvements. There are limits to how many applications can be stored in the limited internal storage of smartphones. Hence, when a smartphone no longer has memory, the user cannot download the app update, thus rendering the user's online transport app unreliable.

Users also report other technology-related inconveniences, such as the need to ensure their smartphones always have sufficient battery, and that their sim cards have enough credits to use mobile internet. These sometimes require additional logistical tasks and expenses for budgetconscious users.

Platform behaviour. The ways platform companies behave and design the systems running online transport apps also surfaced as another source of concern for users. The most corroborated issue is the perception that dynamic pricing sometimes results in rates that are a bit too expensive. Dynamic pricing, also called surge-pricing, refers to the practice of increasing the base fare by a particular multiplier so that the increased fares encourage drivers to accept bookings. The base fare of online transportation, in addition to surge pricing, means that some users find online transport to be more expensive than public transport. For many, higher fares are an acceptable trade-off for better service. However, a few interviewees still voiced that the prices of online transport can hardly compete with those of public transport options such as TransJakarta and commuter line trains. Moving beyond issues of pricing and comparative cost, a few interviewees point out that the algorithm assigns them cars or motorcycles that are too far away, or fails to return a match with a driver. 
Passenger Characteristics. Some issues or factors that impede redress and improvements in online transport are attributable to the passengers' perceptions, preferences, and characteristics. For example, a few users experienced unpleasant or sub-optimal situations such as drivers not driving the registered car, or driving recklessly - and yet these passengers let things pass, preferring instead to avoid the hassle of reporting these issues to platforms. Meanwhile, other interviewees who feel uneasy or scared due to reckless driving feel too shy to confront the driver about it, choosing instead to tolerate greater risks on the road rather than aggravate the offending driver. Consequently, their safety is compromised. A few lady interviewees also confided that they feel unsafe in cars because they are all alone with the driver who is a stranger. Old passengers also have a hard time using online transport since they are not very familiar with the use of the apps, and its navigation functionalities. Hence, they place the wrong pins for pick-up and drop-off and go to the wrong locations. Lastly, several interviewees expressed that when online drivers do something wrong or are rude, they will not always report the driver to the app nor give a low rating out of pity for the driver. This behaviour by users render the ratings system inaccurate. It also undermines the effort of the platform to discipline erring drivers and compel them to give the best service possible, thereby negatively affecting customer service standards received by passengers.

Externalities. Statements of interviewees reveal that the growth of online transport has created negative externalities in Jakarta. For example, an overwhelming majority of interviewees view the increase in online transport as causing more traffic. A good number of them also believe that more online transport vehicles brings more air pollution. In contrast to standard private cars and vehicles, online transport vehicles cause more traffic because they stop to drop-off and pick-up by the road, thereby causing bottlenecks. Moreover, online transport vehicles often have to stand by the roadside as they wait for their passengers to arrive at the pick-up point, or for bookings to be assigned by the app. Hence, they clog lanes that would otherwise be open for traffic, similar to what traditional modes such as angkot and ojek do.

Moreover, one interviewee cites first-hand experience to claim that the fares of traditional ojeks in the areas he frequents have gone up due to the growth of online transport. Traditional ojeks are said to be increasing their fares to compensate for the loss of customers who have shifted to online transportation.

Other Issues. Users of online transport also feel the effects of broader social issues in Jakarta, such as traffic, and the lack of discipline among motorists. These slow down their trips and also increase the risk of accidents. A few have also noted the lack of formal regulation that covers the operation of online transport in Jakarta. However, the Indonesian government is already working on revised regulations for online transport and the digital economy.

Direct participation also revealed that in some online transport cars, the seat belt is unusable because the seat covers do not fit the seats well and thus block the opening of the buckle. It therefore becomes impossible to buckle the seatbelt. In cases where the driver was not driving safely, this paper's main author has often failed to buckle up due to this problem. While interviewees have not mentioned this as a problem, it remains a safety risk that could worsen injuries during accidents. As seen in Picture 1, the placement and size of the seat cover's holes do not match the seatbelt buckle, making it impossible for passengers to buckle up and protect themselves from crashes. 


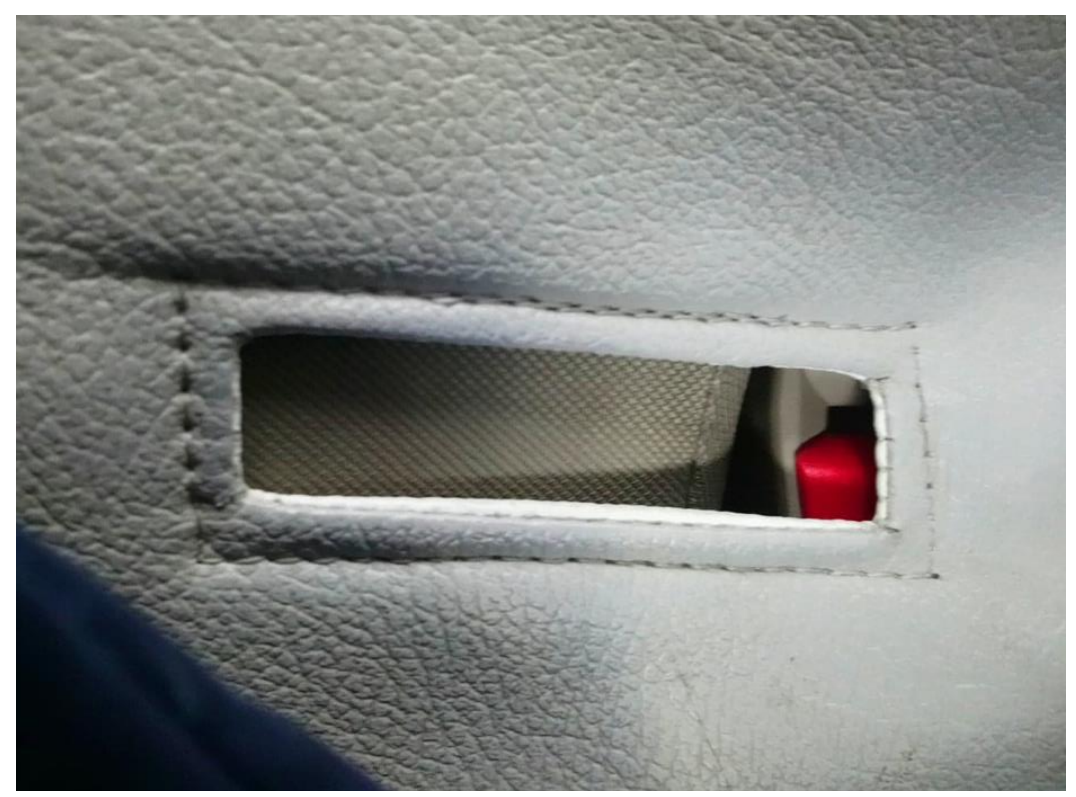

Fig. 1. Unusable Seatbelts. In some online transport cars, the placement and size of the seat cover's holes for the seatbelt buckle are imprecise, making it impossible for passengers to buckle up and protect themselves in the event of accidents. As seen in the

\subsection{Positive Impact on Drivers}

Increased Income Opportunities. Interviewed drivers corroborate that ride-hailing platforms widen their economic opportunities. It surfaced in the interviews that laid-off workers or those wanting to enter corporate positions are hampered by discriminatory corporate practices against applicants older than 30 years old, thereby pushing many to work in the informal sector or remain in lower-paid, unstable jobs. However, Grab and GoJek do not impose such restrictions, benefiting the many middle-aged and older residents in Jakarta looking for work. For some, being an online driver is an opportunity to supplement their household income. In many cases, they earn more as online drivers compared to their previous jobs.

Fairness and Freedom. Online drivers also share that they enjoy greater freedom. If they own the vehicle, they have "no boss" to follow. They can divide their time among work, leisure, and family as they please. They can rest, eat, take a cigarette break whenever they like. Moreover, while drivers deem platform companies to have shortcomings in some areas - as discussed in a later sub-section, interviewed drivers generally feel that platform companies treat them well. For example, the incentive scheme, even if not as generous as before, makes a difference in supplementing their net income. They also acknowledge that the platform companies frequently update the app to implement improvements. In general, the presence of the online transport app is seen positively by drivers since these apps provide income opportunities they otherwise would not have. 


\subsection{Issues and Problems Encountered by Drivers}

Difficulties Arising from Passenger Behaviour. Drivers relate that trip cancellations by passengers pose problems as the fuel and time they spent driving towards the passenger are wasted. They also suffer an opportunity cost as the time and fuel they lost could have been spent on another passenger. Drivers express some frustration when passengers are not at the correct pick-up spot, requiring drivers to communicate and figure out how to meet the passenger. In a few cases, some do not show up without bothering to cancel the trip in the app. In an interesting discovery, a female driver confides that in her experience and those of many other female drivers in their group of female drivers, male passengers refuse to ride when the driver is female. In some cases, they cancel the trip even before the driver arrives, or refuse to take the ride upon pick-up. In some cases, they ask the female driver to let them drive the motorbike instead. Many of such encounters leave female online drivers demoralized.

Passengers can also exhibit a wide array of less than scrupulous behaviours. Some passengers book vehicles to accommodate passengers beyond the maximum limits of the service type. For example, a group of 5 may book a 4-seater car and compel the driver to agree to take them on despite platform rules against this. Unfortunately, overbooking may have implications on insurance because in the event of accidents, not all of the passengers will be covered. A few passengers use ride-hailing apps to transport goods even if doing so violates the platform's rules. In rare cases, passengers do not pay the correct amount. They can also alight farther than the destination they designated in the app. They prod the driver to continue driving "a bit more", in effect reaching their real destination while paying for less.

Platform behaviours. Many of the online transport platforms implement an incentive scheme which financially rewards drivers for accomplishing specific criteria which often includes high ratings, and a target number of trips completed within a time frame, among others. However, accomplishing these requirements to reap the incentives is difficult for drivers, sometimes failing to get the incentives despite pushing themselves to their physical limits. Moreover, some drivers note that the incentives system has given them reasons to doubt its fairness or dependability. For instance, a driver alleges that he has completed all the requirements of the incentives system, and yet the next morning, the app shows that his metrics have gone down, thus disqualifying him from the incentive. They also note that their performance ratings from passengers abruptly plummet for no apparent reason. Drivers are mindful of their performance ratings because those with high ratings receive more bookings from the algorithm, and immediately satisfy the performance rating criteria necessary to garner the incentives.

A consistent sentiment from drivers is that the fares are too low. An often-repeated complaint is that the algorithms penalize drivers by reducing their performance rating when the passenger cancels the trip, even if it was not the driver who canceled and that the passenger's decision to cancel is beyond the driver's control. The algorithm can also assign pick-up places that drivers view as too far, requiring more time and fuel to reach the passenger and increasing the risk of an impatient passenger canceling the trip before the driver arrives. One driver observed that the influx of taxi into the online transport system, exemplified by Bluebird Taxi's collaboration with GoJek called GoBlue, has increased supply, which means that it's now harder to get booking as more drivers compete for demand.

Broader Social Realities. Online drivers corroborate that some form of hostility exists against online drivers; while this varies per driver, this problem does exist. For example, drivers 
of online two-wheeled transport have received ill treatment from conventional ojek drivers, including physical intimidation, verbal abuse, and outright violence, such as being pelted with stones. According to a female interviewee, female drivers also experience the same. Especially during the violent protests by taxi drivers against online drivers in 2016, some interviewees who were already online drivers were scared of such protests. Personnel such as guards of malls and other buildings are occasionally aggressive against online drivers who circle around the said buildings. Traffic enforcers employed by the city government also sometimes demand online driver to leave whenever they stop or park near pavements.

Drivers also voiced opposition to Ganjil-Genap, or odd-even rationing. This is a traffic alleviation scheme in certain parts of Jakarta, which prohibits vehicles from accessing roads on particular days, depending on the last digit in the license plate. Due to this scheme, drivers are forced to take bothersome and longer routes to circumvent the areas under Ganjil-Genap. Interviewees claim this scheme to be ineffective. The well-to-do can buy another car, while those who wish to risk it can simply attach a different license plate to their vehicle and thus outsmart the Ganjil-Genap scheme. Moreover, drivers against the scheme reason that their experience indicates that it only diverts traffic to other areas rather than lessen it. Another gripe with Ganjil-Genap is that it renders useless many of the navigation suggestions of Waze and Google Maps, since these navigation apps have not incorporated the effects of the Ganjil-Genap scheme on navigation algorithms.

The government has also banned the use of smartphones while driving, which may cause drivers to hesitate using navigation. Parking fees - which are ubiquitous in Jakarta - is also a source of awkwardness for drivers. In some cases, the parking fee is collected upon exiting the building or compound after dropping off the passenger. In cases where the passenger does not pay for it, the driver is left to decide between accepting a small loss and paying the parking fee, or chasing passengers to insist they pay the parking fee.

Technology. Drivers mentioned some technology-related issues. Foremost is how GanjilGenap renders navigations apps less reliable. Moreover, some drivers have cheaper and older smartphones with insufficient processing power or memory storage. Hence, the handphone frequently hangs, malfunctions, or fails to run the app properly, making it hard for them to get passengers. Some drivers interviewed also complained about the existence of the "ghost app." Through the ghost app, which is essentially a hacked version of the real app, unscrupulous drivers can fake their location and proximity to users and thus get the most lucrative rides even if they are far away. Consequently, the drivers who use the legitimate version of the apps lose out to the unscrupulous drivers who use the Ghost App.

\section{Discussion: Policy Implications}

This study confirms the findings of previous studies that underline the benefits of online transport on passengers and drivers. However, there are also some difficulties arising from online transportation, that government, the private and sector, and society need to take in mind.

\subsection{Making dynamic pricing algorithms more transparent.}

Users have raised the issue of surge-pricing being too expensive at times. It might be productive for relevant government regulatory agencies to require or request more information 
from platforms on how surge-pricing is computed. In particular, it appears helpful for regulators to know 1.) the exact conditions that trigger surge-pricing 2.) as well as the rationale behind the particular surge multiplier applied. In other words, it would be beneficial if platforms can disclose the parameters of their algorithms such that it is clear how and why the multiplier increases. When the algorithms behind surge-pricing are more transparent, the government will be better able to ensure that algorithms work as platform companies claim, and that prices imposed on consumers are fair. It is not enough for the government to be watchful of base fares alone, it is also advantageous to keep watch on the surge-pricing multiplier, and the fairness and frequency with which it is triggered.

\subsection{Understanding the defects of the ratings system.}

The ratings system in the app allows users to report problems to the platform, or give low ratings to drivers. This system is a way of disciplining drivers and compelling them to offer high service standards, or else receive low ratings and be penalized by the algorithm. However, there is evidence that sometimes, passengers neither give honest ratings nor report problems. They pity the drivers, fear that drivers might lose their jobs, or simply do not wish to bother. Consequently, some offending drivers are not called out, and their undesirable behaviours remain uncorrected. Hence, while the ratings system does compel good behaviour from drivers to a reasonable extent, it does not seem sufficiently reliable.

\subsection{Inspecting vehicles (or other alternatives) to catch vehicle deficiencies}

As discovered in interviews and during extensive fieldwork, there are online cars and twowheeled vehicles with relatively minor issues such as lack of hygiene to possibly catastrophic ones such as unusable seatbelts in cars and faulty helmets in motorbike taxis, which may one day cost lives. Platform companies such as GoJek and Grab have existing processes to ensure that the vehicles used in online transport meet a minimum standard criteria such as being sufficiently new, often measured in terms of the year of the car model. However, both government agencies and platform companies should consider ways to make sure that cars are inspected according to a rationalized criteria that goes beyond the newness of the vehicle. In this way, the defects mentioned above can be caught and remedied. Other items can be included in the criteria, such as the good condition of signal lights, the lack of odors in the vehicle apart from physical cleanliness, and the cleanliness of aircon filters. Jakarta's pollution means that passengers inhale unhealthy air if the air conditioner filters are not frequently cleaned. If inspection is not feasible, then platforms should communicate to their driver a list of criteria that their vehicles should follow. Due to its inaccuracy, a ratings system is not a substitute for more direct measures such as inspections and frequent reminders to drivers to ensure the highest quality of service possible.

\subsection{Educating passengers}

The research uncovered that there are a range of passenger behaviours that make the life of drivers harder. It may be helpful for platform companies to embark on a more concerted information campaign to educate passengers on proper etiquette in online transportation. It does not need to be expensive or complicated. Platforms can launch inexpensive social media campaigns or request popular TV and radio channels to conduct interviews with platform officials who will call on the public to adhere to online transport etiquette. 


\subsection{Assessing the Ganjil-Genap Policy}

Authorities may also want to consider the complaints of drivers about the inefficacy of the Ganjil-Genap Policy in alleviating traffic and its negative impact on online transport, for possible amendments to the policy.

\section{Conclusion}

We conclude this paper by highlighting the key empirical takeaways and possible policy implications arising from this study. Users benefit from online transport through increased time savings, better convenience, comfort, and safety, and also through an improved capacity to pursue new activities. However, they experience difficulties from online transport, specifically due to driver behaviour, platform rules, and technology issues. Moreover, interviewees also observed negative externalities from ride-hailing in Jakarta. On the other hand, drivers also experience positive and negative impacts. Drivers report increased income opportunities. They also enjoy more freedom in their work, and feel that platforms treat them well in many aspects. However, drivers suffer from passengers' untoward behaviour, and some aspects of platforms which they see as unfair or sub-optimal. They also face technology-related constraints, competition from unscrupulous drivers using the Ghost App, as well as broader social issues such as the Ganjil-Genap scheme, and anti-social behaviour from those opposed to online transportation.

To mitigate some of the complaints by users and drivers, policymakers can consider several steps such as increasing the transparency of dynamic pricing, understanding where rating systems might be misleading, and instituting physical inspections of vehicles. Platforms should also take the lead in popularising a code of conduct among passengers to ensure their drivers are not put in unfair situations by unscrupulous passengers. It might also be worthwhile for officials to revisit the effectiveness of the Ganjil-Genap policy.

If the problems uncovered in this research here are addressed, then perhaps Jakarta can unlock more fully the potential of ride-hailing platforms for social good.

\section{References}

[1] Hanifah S. Analyzing the Factors Influencing the User Intention Toward E-Commerce Based Transportation: A Study on Go-Jek. 2016.

[2] Maharani M, Chan A, Tresna PW. Comparison of User Experience on Go-Jek and Grab Mobile Apps (a Study on Pt. Go-Jek and Pt. Grab Indonesia Consumers in Dki Jakarta). In: Bandung, Indonesia; 2017.

[3] Alamsyah A, Rachmadiansyah I. Mapping online transportation service quality and multiclass classification problem solving priorities. In: Journal of Physics: Conference Series, Vol 971. IOP Publishing; 2018. p. 012021.

[4] Anastasia S, Budi I. Twitter sentiment analysis of online transportation service providers. In: 2016 International Conference on Advanced Computer Science and Information Systems (ICACSIS). Malang, Indonesia; 2016. p. 359-65.

[5] Harsono N. Grab unlocks Rp 46t in additional income for drivers, merchants: Survey. The Jakarta Post. https://www.thejakartapost.com/news/2019/04/11/grab-unlocks-rp-46t-in-additionalincome-for-drivers-merchants-survey.html. Published April 11, 2019. Accessed June 29, 2019. 
[6] Medeiros RM, Duarte F, Achmad F, Jalali A. Merging ICT and informal transport in Jakarta's ojek system. Transportation Planning and Technology 2018;41:336-52. DOI:10.1080/03081060.2018.1435465.

[7] Gunarwati DT, Kurnia L. A study on how Uber seizes the transportation space in Jakarta. In: Budianta M, Budiman M, Kusno A, Moriyama M, eds. Cultural Dynamics in a Globalized World. London: Taylor \& Francis Group; 2018. p. 761-75.

[8] Bryman A. Social research methods., 3rd ed. Oxford: Oxford University Press; 2008. 